\title{
Chapter 12 \\ Restorative Design for Heritage \\ Requalification: Selected Roman Works
}

\author{
Luciano Cupelloni
}

\begin{abstract}
The theme is the urban re-qualification, applied in particular to the architectural heritage and the public space. The goal is the ongoing challenge of outlining a new perspective aimed at "common good" and sustainability. The instrument chosen is the "environmental technological design," understood as a cultural, scientific, and social position, that is, as a position on the role of architecture. The contribution reiterates the urgency of restoring the transformative power of the design mission to the project, too often reduced to a set of technical compilation procedures. In the best cases, a position that is lost in the complication of procedures, in the extension of time, in the waste of economic and human resources. A crisis of the project as "anticipation" of progressive scenarios, precisely in the most acute, ever more serious phase, of the urgency of the reorganization of urban systems, with a view to environmental, social and economic sustainability. Not a recent urgency, today only brought to light, dramatically, by the reality of the SARS-CoV-2 pandemic. Among the solutions, the design experimental research, well beyond the objective of flexibility, up to the notion of "functional indifference," understood not as shapeless neutrality, but as the maximum functionality of spatial, architectural and urban quality.
\end{abstract}

Keywords Architectural and Urban Regeneration · Historical Heritage · Public Space $\cdot$ Environmental Technological Design

\footnotetext{
L. Cupelloni $(\square)$

Department of Planning, Design, Technology of Architecture, Sapienza University of Rome, Rome, Italy

Cupelloni Architettura, Rome, Italy

e-mail: lucianocupelloni@1c-architettura.com
} 


\subsection{Introduction}

\subsubsection{Project as Layering}

This contribution deals with architectural and urban restoration, applied in particular to heritage buildings and historical public space. The goal is the ongoing challenge of outlining a new perspective aiming at "common good", as well as sustainability. The instrument chosen is the "Environmental Technological Design", understood as a cultural position on architecture, as a disciplinary position in the academic sphere, and as an operational everyday life of the architect's profession.

The urban complexity of the city of Rome is the context in which the experiences described below mature, not only the application and verification of criteria and methods outlined in the research, but also the same definition of original tools and design solutions, largely in a wider context, and precisely from the specificity of the individual cases.

In this perspective, I describe the forms and ways through which - over the years - I have come to draw from studies, experiences, and even from particular emotions, a personal declination of architectural and urban restoration that arises from the profound relationship with the historical reality of architecture, always rooted in its places. When the place is the city of Rome, this relationship becomes a vital relationship, fuelled by a narrative that Rome expresses like no other city in the world (Cupelloni, 2014).

The history of the city is stratification, replacement, reorganization. It is a continuous process, a creative trend, which implies and contains destruction. We would not have extraordinary monuments if other equally important ones had not been torn down or transformed (Cupelloni, 2010).

This is the "tradition" of the city of Rome, the reason not only for the uniqueness and exceptional quality, but also for its modernity.

I still remember, after more than 30 years, the emotion felt in going through the excavation conducted by Christoph Luitpold Frommel and Richard Krautheimer in the courtyard of the Palazzo della Cancelleria. I saw the discovery of the early Christian Basilica of San Damaso below the medieval level, and the fifteenthcentury floor of the church, clean-cut by the will of Cardinal Raffaele Sansoni Riario della Rovere at the end of the 1400s, just to build the great palace. The Basilica was an important construction, it was cut horizontally no more than two meters from its footfall. The excavation found it intact, with its frescoed walls, the altar, the floors and the sepulchral stones. And under the Early Christian Basilica, the remains of the great plague epidemics, a tomb from the Republican era and the Euripe riverbed. All immersed in water in an underground and transparent vertigo.

Another case, much more recent, on the occasion of an extraordinary opening of the cistern of the Seven Halls. The cistern is an engineering masterpiece serving the Terme di Traiano. The "Terme", as well known, were built above the Neronian domus - the Domus Aurea - in turn the result of the great fire of 64 AD. And on the vaults of the cistern, a domus, which reorganizes the previous utilitarian structures 
with great breadth. Once again, a wonderful stratification, a vertical section of the Roman culture.

If architecture, as a result of human history, exists only in its place, and if its place is no other than the city, then, there cannot exist an international architecture which we have long known failed in the version of the International Style but also in today's global unification - but only an architecture capable of grasping the value of memory and at the same time to understand the need for listening. Consequently, the architect must first of all be a "discoverer of stories and places". And not for cultural or narrative reasons, but for a specific goal: to give or return quality to the city as a result of its history, and above all, quality to human life in its city.

In many other cases, on the occasion of projects on monumental complexes of medieval layout progressively transformed, at least until the nineteenth century, from defensive structures into noble residences or on industrial architecture between the late nineteenth and early twentieth centuries, my experience of stratification is daily. In the initial studies and even more in progress, during the realization phase, when the historical knowledge, the archival documents together with the drawings and the thousands of project data overlap, as in filigree, repeatedly, on the matter of the artefacts on which you go to operate. A real cognitive process that does not end in the library or in the archive but which, passing through the surveys, the field analyses, the "section" of the factory, uses observation and the many methods of tests and essays to reach the design solution. From the subtle at times elusive relationship with the artefact, all intellectual although intimate for the inevitable relationship with the architects, we move on to "body to body". From the clean line on paper, from the multi-coloured graphic overlaps, from the dynamic behavioural models, from the representations that approximate reality, we move on to matter, to the subsoil, to the physicality of the space where first dust and then light play a decisive role in that long, dilated, moment of knowledge, of clarification of theories and choices, which is the construction site. The intuition of new spatiality is completed, the set of techniques becomes a system, the geometries and dimensions are compared and all this does not contradict the level of depth and completeness of the project. On the contrary, this is the condition for timely verification, for constant control and development, all the more so if the project has consciously set itself the theme of stratification, of a contemporary doing that preserves and innovates each other, in morphological, technological and environmental terms.

Simplifying, but not entirely, the quality of the historic city has much to do with the terms of sustainability and human well-being. It is enough to reflect on the quality of urban structures, where axes and fires trace the large scale conforming it with fabrics on a human scale, where the great property of kindness translates into parks and public institutions, where architecture configures streets and squares, and these through the arcades and internal courts mediate the relationship between the city and the house.

We can actually say that often "quality is there", before our eyes. In the passive behaviour of masonry or wooden constructions, in the performance of the wall thicknesses, in the conformation and material of the roofs, in the arrangement and 
size of the holes, in the intelligence of many minor components such as shutters or shutters, in the regional variants, to protect from heat or cold.

Certainly, these are qualities that are not reproducible as such, but that we must be able to recognize and measure - in the specificity of the cases and conditions of the site and context - setting ourselves the goal of enhancing them, at the urban level, with innovative solutions and at the same time historically consistent.

For the architectural heritage, it is necessary to decline passive technical solutions and active systems eco-efficient, selected or better designed in accordance with the peculiar architectural historical characteristics of the good. The latter aspect is particularly complex. Very often, it has been practiced, reductively, only as energy efficiency. It is an ambiguous, if not incorrect, the approach that applies the logic of retrofit, understood as applying standardized solutions or technological devices, designed for new construction, "overlapping" the existing ones.

On the contrary, the architect is called to be the architect of a process where the project is knowledge and interpretation, a complex outcome of specific conditions and general needs, of never mechanical prefiguration and critical innovation, of constant development, in the design phase and if not in progress, certainly in the life cycle of the work, exactly as history teaches us.

\subsubsection{Architectural and Urban Regeneration}

Having ascertained the benefit of saving land, having calculated the multiple economic advantages linked to the presence of already infrastructured urban areas, both inherent in the intervention on buildings, there is no doubt that the environmental issue involves a radical paradigm shift. It is quite clear, particularly in the Italian situation, that the theme of intervention on heritage cannot fail to decline according to the broad meaning of "environmental technological requalification", positively interpreting the limitations - albeit sacrosanct - of protection and conservation.

With this in mind, the field, the themes and the chances of intervention on heritage broaden significantly. Certainly, for the often-exceptional quality of our goods, for the profound cultural significance of the protection and conservation of arts and techniques, material testimonies, stories and memories. But above all, for the benefits associated with that mix of conservation, innovation, and functional conversion that characterizes the most advanced interventions, generating positive margins at the architectural level also in terms of eco-efficiency. And for the even more significant opportunities in terms of environmental, social and economic sustainability connected with the intervention on urban fabrics.

Although in very different terms from other regions of the world, today protagonists of the processes of change induced by globalization, in Italy, the theme of the city cannot fail to pose itself in totally opposite ways to those typical of post-war industrialization, the engine of widespread well-being and population growth but also of often uncontrolled expansion, cause of territorial imbalances, of extensive 
destruction of the natural heritage, of profound alteration of historical urban structures.

The roles and functions of the big cities have changed, in many European countries, since the nineties of the last century, virtuous processes of urban and territorial reconversion have been experimented. Driven by the response to negative economic trends as far as scientific research and the desire for innovation are concerned, the recent history of European capitals is unmistakable with the stasis of Rome and with the same dynamics of Turin and Milan which, however - unique in Italy - have been able to redefine identity and models. Even more evident - if compared with the chronic crisis of the major Italian production sites - is the ability to renovate "failed" urban centres, such as Marseille or Liverpool, Barcelona, Malmö or Bilbao. And even more complex cases such as the Ruhr industrial region.

In all cases, with the differences in specificity, success coincided with the redevelopment of artefacts and places, with the creative definition of new meanings, roles and functions based on the updated reading of economic processes, with great attention to the quality of the architecture and public space, technological innovation and job creation, social cohesion and citizens' health.

In Italy, "urban regeneration" is largely just a slogan. The absence of structural policies and the inability of incentive actions to trigger real planning seem to entrust the initiative rather than to the State to the territories, at all scales, regions, cities, municipalities, under penalty of degradation.

Although today $75 \%$ of construction production derives from maintenance and renovations, compared to $58 \%$ in 2007 , Italy is the sixth European country in the ranking of land use, not only in violation of the European target zeroing by 2050 but also with the well-known consequences in terms of erosion of rural landscapes, loss of ecosystem services and vulnerability to climate change.

Rather than urban regeneration, it is the regeneration of an obsolete and inefficient residential heritage in many ways. Operation necessary but insufficient. This is demonstrated by the report "Urban ecosystem 2019" which investigates the urban quality of 104 Italian cities with respect to parameters such as air, water, waste, mobility and the environment. Among the most virtuous cities we find Trento, Mantua and Bolzano, while Milan is in 32nd place, although in first place for public transport and for efficient use of the soil and in sixth for the presence of trees in the city and in seventh for capacity of water purification. If Palermo is in 100th place, Rome does not shine with its 89th.

This highly synthetic picture is completed by the seismic vulnerability and energy inefficiency of a complex heritage that includes countless monuments, infinite architectural assets and an aged and modest if not low build quality construction stock. And when we talk about architectural goods, we mean urban works and systems of various order and degree, ancient and modern and even contemporary. 


\subsection{Case Studies and Design Experimentation}

\subsubsection{Environmental Technological Requalification}

Very often, in the course of a long personal experience, contact with situations of degradation of artefacts but also of the urban context prevailed. Negative conditions, originating not from lack of quality but from a widespread, serious, loss of quality. Very little care, almost total absence of culture, if not the same notion of maintenance, lack of planning of interventions, widespread impromptu decision-making of government.

All this makes the architect's work complicated, overloaded with expectations, inevitably frustrating even when, in the immediate future, the results are positive. For these reasons, the theme of architectural and urban redevelopment arises as the need to translate increasingly complex objectives into viable but clear solutions, tracing each time the right "measure" of the project. A project that, overcoming the basic category of recovery, is able to give back to the object of intervention whether it is a building or an urban environment - the lost qualities but also to add new ones in a relationship of mutual and dynamic.

With this in mind, the redevelopment project certainly provides for conservation, does not exclude addition and demolition, obliges structural rehabilitation and seismic improvement, involves functional conversion and regulatory and performance adjustment.

The experiments described below contain this complex cultural and technical condition. In urban, architectural and technological terms, these are projects aimed at finding a coherent balance between conservation and innovation, between restoration and new architecture, between settled identity and contemporary meanings. Projects that aim for environmental sustainability, preserving signs and materials, improving structures and renovating figures, reorganizing spaces and functions to meet new needs, translating the spirit and characters of what remains into an additional architecture, in turn not least the moment of historical stratification.

Experiences such as the "City of the Other Economy" at the Testaccio slaughterhouse, a series of interventions in the Garbatella district and the cultural centre called "Piazza Elsa Morante" outline, each in a different way, original forms and redevelopment solutions, as motivated by cultural, technical and scientific criteria and tools.

\subsubsection{The Case of Gioacchino Ersoch's Slaughterhouse}

In the old slaughterhouse in Testaccio, the major work of Gioacchino Ersoch (1815-1902) (see Box 12.1), the project for the "Alternative Economy City" translates an original program into an intervention that tests the extreme limit of renovation under strict monumental limitations. Operating on the Pese del Bestiame 


\section{Box 12.1}

The Ersoch Slaughter House complex is located in Rome into the Testaccio district, closely behind the Aurelian walls between the Cocci's Hill and the Tiber river. Realized in only three years between 1888 and 1891 according to the project of the architect Gioacchino Ersoch (1815-1902), it grows on an area of 10 ha of which $4000 \mathrm{~m}^{2}$ indoor. The work, that reflects the transition from classicism to modernity, is characterized by large pavilions and light rooftops presenting traditional brick curtains, travertine elements and plasters, as well as innovative iron and cast-iron structures, with a sophisticated balance between monument and industrial rationalism. The complex, dismissed in 1975, became protected only in 1988. For almost two decades, numerous projects have been accompanied by lack of attention, and widespread degradation took over. In 2002, the City of Rome devoted the complex to cultural and educational public services, starting a deep renovation program still hardly in progress (Cupelloni, 2011).

(cattle weights) construction, on the long Ersoch's portico from 1888 and the shelters from 1928, rare Roman examples of structures in iron and cast-iron, the architectural project includes restoration and addiction, structural rehabilitation and eco-efficiency, conservation of the facies and new sign, in the context of a unitary, spatial and material redefinition (Nicolini, 2008). Already a symbol of the original Ersochian relationship between tradition and innovation, the relationship between neoclassical buildings and innovative iron and cast-iron structures is enhanced and interpreted by the contemporary design of the restoration project (Cupelloni, 2011) (see Fig. 12.1).

The central core of the long front extends for more than $200 \mathrm{~m}$; the small square between the modules makes evident the interchange between new volumes and open or only covered spaces, distinguishing the original segments from those that add new signs and elements to the existing structure (Cupelloni, 2011) (see Fig. 12.2).

The response to the functional program - 12 independent cultural and commercial activities on an area of $3500 \mathrm{~m}^{2}-$ is the covering of the space between the portico and the balconies with a new steel structure, that transforms the existing rooftops and the intermediate voids into an additional area. Along the linear development, more than $200 \mathrm{~m}$ long, the new skin is divided into different and flexible units that alternate covered or enclosed open spaces - clearly featuring the original parts - as well as the new signs and elements, added to the pre-existing parts (Cupelloni, 2011).

The intervention activates a meticulous conservative restoration of the Pese del Bestiame building and the adjacent portico, and a complex revamp of the structures in iron and cast-iron (Cupelloni, 2011) (see Box 12.2). 


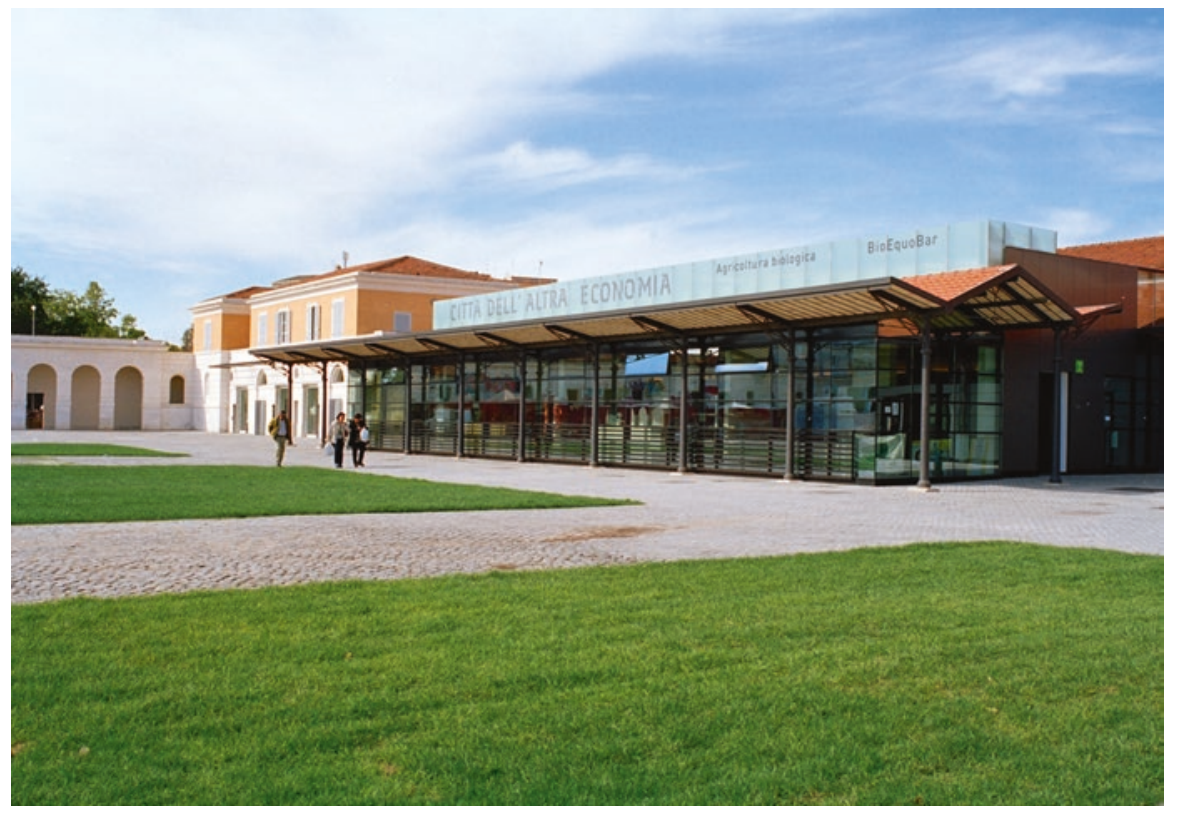

Fig. 12.1 "Alternative Economy City" at the Slaughterhouse of Testaccio (2007), Rome. Photo by Roberto Bossaglia, Cupelloni's archive

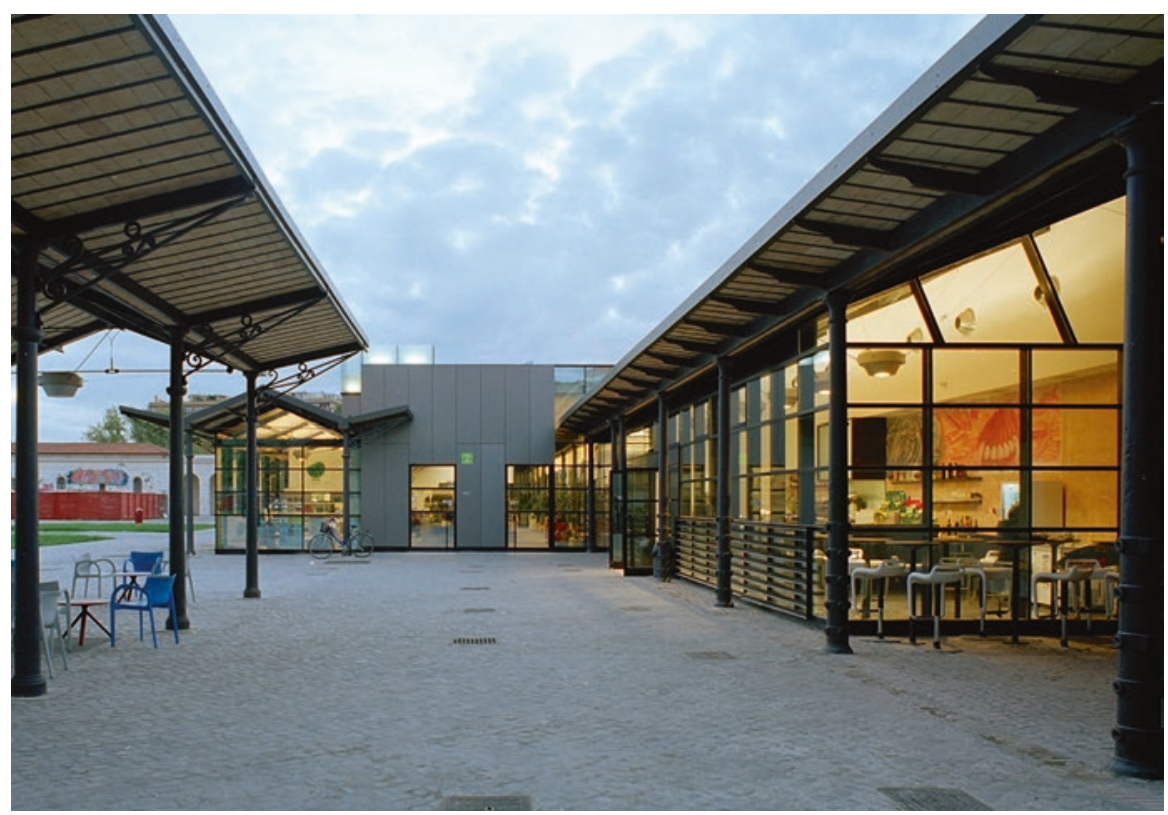

Fig. 12.2 "Alternative Economy City" at the Slaughterhouse of Testaccio (2007), Rome. Photo by Roberto Bossaglia, Cupelloni's archive 


\section{Box 12.2}

The METALOCK system (1947, Coventry, UK) is a solution for the cold repair of cracked and broken fusions. It consists of applying shaped bars of steel alloy, with a high nickel content, in small corrugated cavities - carried out with given intervals, perpendicular to the fracture - associated with threaded holes along the fracture line, in which screws of the same alloy are inserted. Used in industrial contexts (machineries, pumps, boilers, etc.) the system was used for the first time in Rome on the cast iron columns on the roof of Campo Boario (Kaltenback, 2009; cited in Cupelloni, 2011)

The new covered spaces, between the old sheds, have been realized with an iron anti-seismic structure completely prefabricated and partially assembled in factory in order to facilitate the final assemblage in relation to the pre-existent structures (Randaccio, 2009; cited in Cupelloni, 2011). The new structures are statically independent from the older ones, and technically reversible.

The unique combination of old roofs and new volumes is enclosed by a glass shell, that - also thanks to the open space organization - ensures the maximal transparency to the originally open structures. Glazed facades and skylights lead to an efficient control of the thermal behaviour, benefitting from orientation and position, which are obviously not modifiable conditions. The control of the impact of sun/air made it possible to maximize the solar heat gains during the winter time, and to minimize the solar radiation during the summer. General and detailed solar diagrams informed the design of the sunscreen system. The glazed south-east façade is protected by a system of horizontal plates, located on the lower part, completing the shading effect of the existing rooftop. The openings system of the new roof is a technological solution that provides natural light without summer overheating, while allowing for the positioning of PV panels (Cupelloni, 2011).

The sheds facing north-west are protected by vertical panels and horizontal projections, limiting the overheat in the summer's afternoon. Located besides the sheds, the flat roof-lights, covered by an inox steel multi-perforated double slab, provide the total protection from solar radiation during the summer and allow for the maximum entrance of direct radiation during the winter, while diffusing luminosity in every season. Studies for the protection of the glazed façade from direct solar radiation, were coupled with aerodynamic flows analysis. The analysis has resulted in a regenerative climate adaptive design where the flows are conveyed, from the frontal openings, and from the north-oriented rooftop openings, in the shaded zone, providing summer refreshment and air exchange (Toffolon, 2008; cited in Cupelloni, 2011).

The optimization of thermal effects and natural lighting leads to the use of stratified insulating glazing systems, low-E with neutral reflection, set on extruded aluminium profiles with thermal cut, with hinged motorized leaves.

Aiming at the reduction of heat losses, hemp panels are used on the roof and on the facades. Low-energy lighting devices are used for artificial lighting, with high 
performance and long life: mainly fluorescent lamps controlled by light sensors, and in some spaces, metal halide lamps. The entire system of furniture and equipment, realized most on design, uses environmentally conscious processes and materials. The complex is equipped with 7 thermo-mechanical independent power houses, with high-performance heat pumps air/water and UTA with dynamical recovery $>70 \%$. The nocturne natural ventilation contributes in the summer to the heat reduction inside the building. The complex benefits from a photovoltaic system based on 166 silicon panels, plumb free, with an output of $180 \mathrm{Wp}$ peak power, 30 $\mathrm{kWp}$ total power and 40,000 kWh annual production; it reduces the $\mathrm{CO}_{2}$ emissions of about 25,000 Kg/year (Cupelloni, 2011).

\subsubsection{The Case of the Street of the Seven Churches}

In the Garbatella district, in the heart of the urban fabric of the first "garden city" (1920-1935), a historic track, a neglected park, streets and squares, upset by too many cars, have returned to quality, thanks to the accurate design, the attention paid to the materials, and the attempt to put a limit on car mobility, returning public space to the people who live there. The historical character of the Street of the Seven Churches ("Via delle Sette Chiese") and the presence of significant archaeological, architectural and environmental emergencies gives rise to a project that orders a new urban scene, which tells its story (see Fig. 12.3).

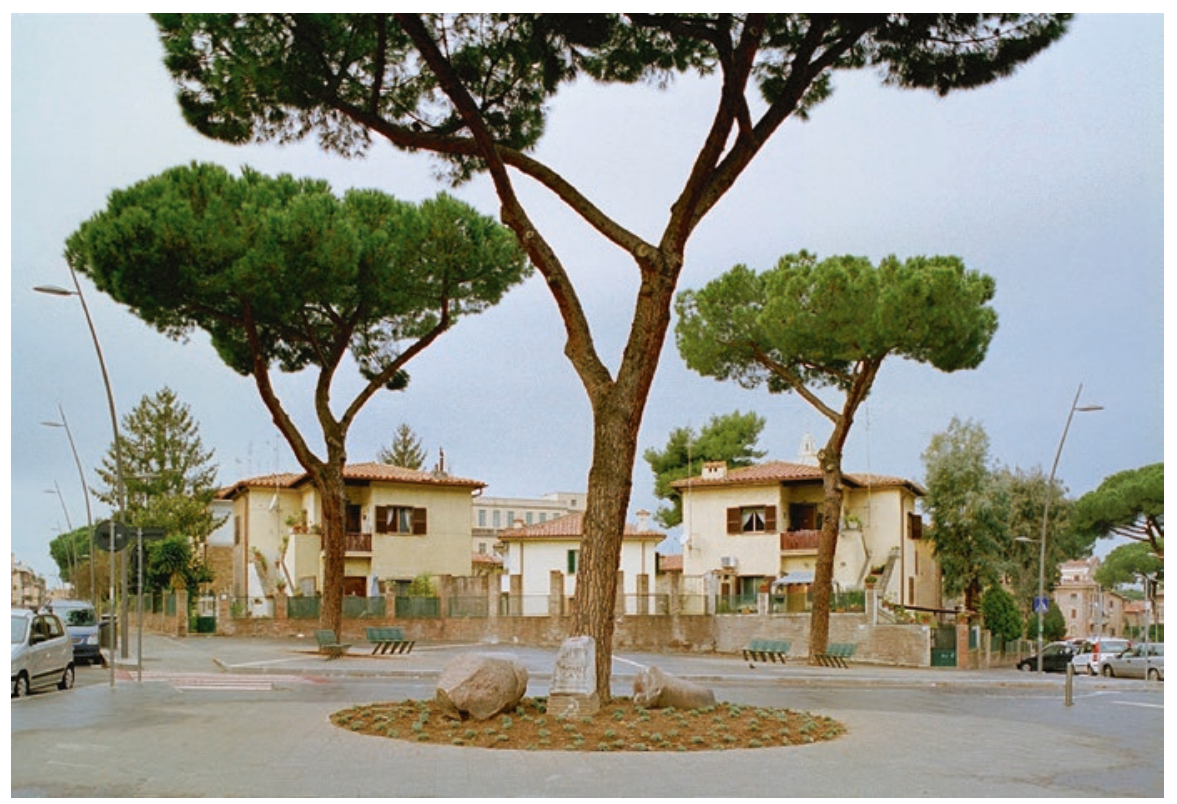

Fig. 12.3 Saint Eurosia square, Garbatella (2002), Rome. Photo by Roberto Bossaglia, Cupelloni's archive 
A neighbourhood garden, on the extras of the ancient catacombs, among the unique architecture of Garbatella, becomes a place of new social, spatial and perceptual experiences (see Fig. 12.4).

The project is once again based on the conviction that the values of history - the environmental emergencies, some monumental elements and the architectural fabric of the Garbatella which as a whole insist on the Street of the Seven Churches must be placed in close and coherent relationship with the contemporary culture and citizens' needs (Andreucci, 2015).

The search for a sensitive balance between the desire to preserve a "memory" of the place and the proposition of formal and technological solutions oriented to "innovation" translates on the one hand into the enhancement of urban stratification and its cultural and morphological values, from the more in new responses to urban, social and functional needs.

The "open" road on the San Paolo hill, the road as an itinerary started by Saint Filippo Neri which then became jubilee - first in the countryside, then as a caesura of urban development - together with the first and second Garbatella, became the theme of the project.

The Street of the Seven Churches is characterized by the presence of singular natural elements - a tufa cliff, green spaces, some tall trees - and by a widespread and significant architectural quality originated from the interventions of the Istituto Popolari houses made in the 1920s and 1930s, designed by the architects Gustavo Giovannoni, Innocenzo Sabatini, Plinio Marconi and others.

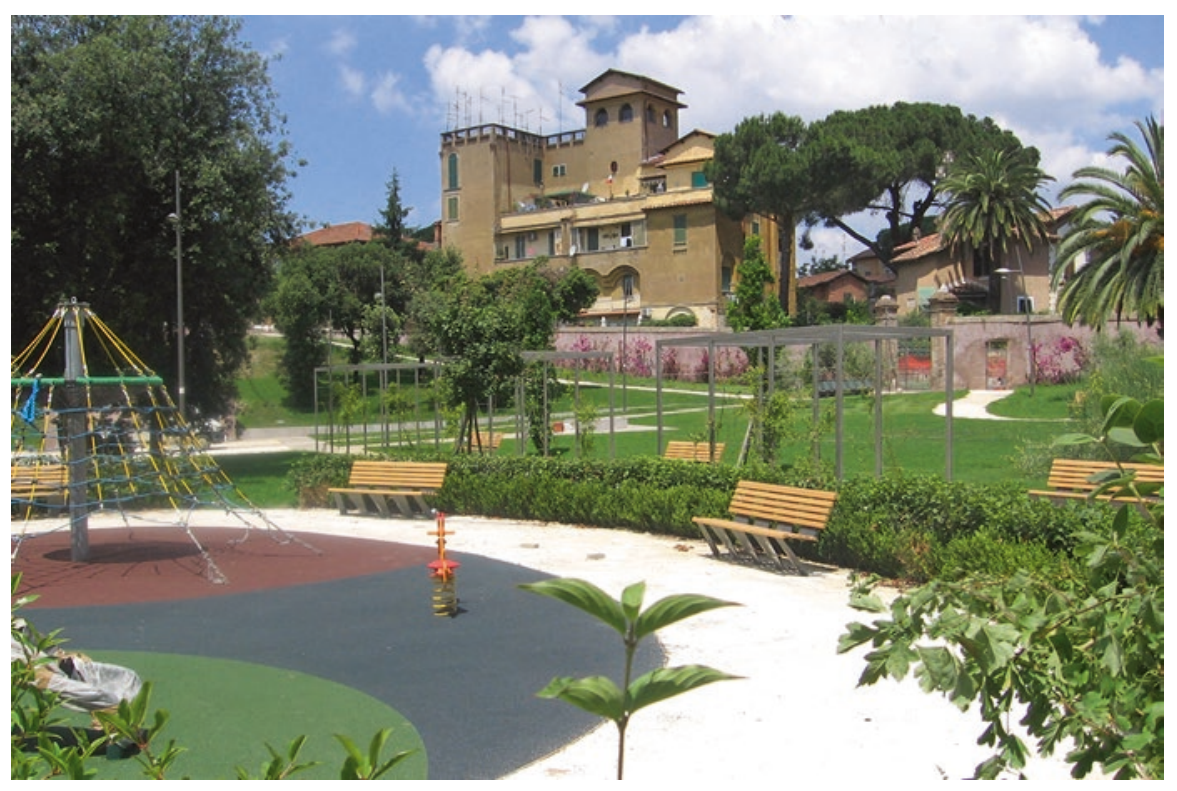

Fig. 12.4 Commodilla Catacombs Park (2008), Rome. Photo by Cupelloni's Archive 
The project therefore takes the road as a historically changing complex place, as a succession of events and scenarios where the values of the past and present give rise to a varied path, in terms of quality and spatial conditions. A marked or just defined path, unitary or progressively fragmented by the different characteristics of the building. Clear and noble those of the early twentieth century, anonymous those of the post-war period in a sequence of fabrics on a human scale or of open spaces determined by vehicular circulation.

Unity and fragmentation, simple connection traits, significant areas and "objects": this is the identity of the place. Therefore, the redevelopment is based, in the first instance, on the desire to make the course certainly legible in a physical sense but above all the "condition of the journey" - authentic genius loci-differentiated and in several places completely lost.

The goal is that of a "promenade", of a path where it is pleasant to walk, stop, and meet. In parks, in squares, along large sidewalks protected from car traffic and well lit. Morphologically, the new route is an "interrupted line," a piece of road rediscovered, a metaphor for archaeological excavation. Physically, it is a rectilinear paved path, of variable width, distinguished by the didactic clarity of the sign and the material used.

The pavement is in fact characterized by a central cobblestone strip that identifies the path, flanked by a basalt lane reserved for the disabled or mothers with strollers, shaded - in several places - by trees and long flower beds with shrubs.

With this in mind, the project proposes relationships and establishes new relationships with the architectural emergencies and episodes that characterize the path, with the aim of responding to the needs of spaces intended for meetings, for children, adults and the elderly. And in this sense, the path is flanked, in addition to the parks, with small rest areas for passers-by, panoramic points, visual angles and real pedestrian squares.

Consequently, the road journeys have been reorganized by eliminating the crossing flows of the neighbourhood, calming speeds and redesigning the roadway with particular attention to the organization of parking areas and green spaces.

In addition, the historical character of the street and the presence of significant archaeological emergencies make it interesting to propose, again, a characteristic aspect: the custom of the architects of Garbatella to arrange on the urban scene the marble remnants found during the excavation of the foundations of the buildings.

In the project, artefacts stolen from the depots, carefully located in new urban fires, and floor inscriptions on stone allow the road to tell its story, through a path full of spatial and perceptual experiences.

Consistent with the position of the project, the choice of materials: preservation of memory and modernity translate into a construction that uses traditional materials - Roman cobbles, basalt, granite and travertine for the floors - but also the steel, combined with wood, for the furnishing elements.

These in particular are made up of seats formed by a metal sheet, folded and perforated to avoid water stagnation with overlapping wooden slats, painted in green to recall the traditional Roman bench or to leave natural inside the park of the Catacombs of Commodilla. 
In coincidence with the entrance to the park of the Catacombs, a small square was created, enhanced by inscriptions on the ground, benches and lights facing the entrance to the park and the most important buildings.

The park overlooks the ancient settlement of the Catacombs of Commodilla. Another historical stratification which will be followed by the discovery of important archaeological remains which have undergone restoration. The result is an archaeological and sacred space to which large green spaces and areas equipped for socializing and playing are associated.

\subsubsection{The Case of the Laurentino 38 Neighbourhood}

The intervention called "Piazza Elsa Morante" is part of an extensive redevelopment programme of the "Laurentino 38" (1971-1984), neighbourhood, the result of a plan of economic and popular housing, public and private, for about 32,000 inhabitants, obviously marked by the problems typical of the metropolitan suburbs. In this case, the intervention works on the contemporary urban fabric (see Box 12.3).

The project's programme consists in the realization of an Arts Centre interpreted as a new social infrastructure, that is, a "piazza." The intervention site is a parking lot, covering more than two hectares: twice the size of Piazza Navona, four times the size of the Termini train station's gallery, in Rome. Crosswise, it is a marginal section at the base of a built-up hill; longitudinally, it is a low plane marked by a row of stone pines (Cupelloni, 2011).

These characters and various other activities dictate the structural rules, limiting the potential building area to a long and narrow strip, and this low position - lower of the surrounding streets - closes off views which just a few meters higher are extensive and evocative (Cupelloni, 2011).

The size of the area is a resource, and at the same time a problem to be resolved, to avoid that "out-of-scale" between man and the urban structure which is one of the major problems of the neighbourhood (Cupelloni, 2011).

In this scenario, the project operates through horizontal planes: the zero quota, pedestrian and featuring greenery, and a second quota on slender steel columns,

\section{Box 12.3}

The "Laurentino 38" neighbourhood was designed by a team led by the architect Pietro Barucci, in 1971-1974. The construction began in 1976 and ended in 1984. The general layout is characterized by the repetition of a basic module, consisting of various, almost identical, buildings, connected by bridges, arranged transversely to a large ring road. In 2006, the Municipal Administration demolished three of the eleven bridge buildings, which had become symbols of social and environmental degradation, and started the cultural centre project (Cupelloni, 2011) 
made up of precise planes, just below the foliage of the pine trees, lapped by green edges. Between these two floors, the new spaces unwind: the newspaper library, the médiathèque, a 200-seat theatre and, on the opposite side, a 350-seater arena. Three buildings designed as open spaces, arranged behind a long metal wing which, crossing them, separates the park from the adjacent street. The linear arrangement produces three spatial environments, connected by the transparency of the buildings, into which the activities of the Cultural Centre articulate: the "water piazza," the main access to the Laurentino 38 neighbourhood, the "little wood" between the library and the médiathèque, and the "multimedia piazza" between the médiathèque and the theatre (Cupelloni, 2011) (see Fig. 12.5).

For a neighbourhood which programmatically has no focal point, the project does not propose an unrealistic, traditional piazza, but a series of contemporary "piazzas," Each marked by large steel pylons carrying the photovoltaic panels: "cubes of light" as urban signals (Costa, 2011; cited in Cupelloni, 2011).

The route which connects the "piazzas" extends towards the natural reserve, reminding of the typical Roman relationship between city and countryside: simple green mounds - located on the south side with shading and wind protecting functions - bring variety to the views, organizing a sequence of meeting spaces, with wooden letters that write "P E M O R A N T E". The intervention makes use of ecological and photo-catalytic materials, produces electricity through photovoltaic systems and accumulates rainwater to irrigate the park. The attention to sustainability is expressed particularly in terms of eco-efficiency: orientation and solar radiation studies; technical solutions for the insulation of the concrete skin; transmittance

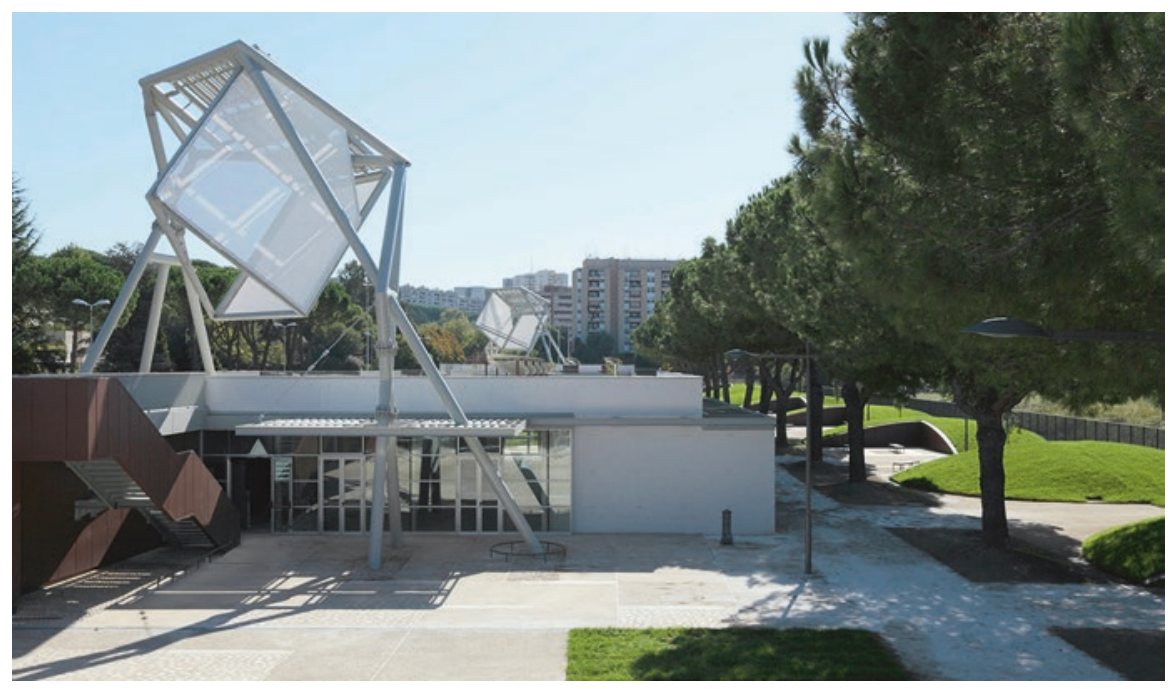

Fig. 12.5 Elsa Morante Cultural Center, Laurentino 38, Rome Capital. Photo by facetoface 


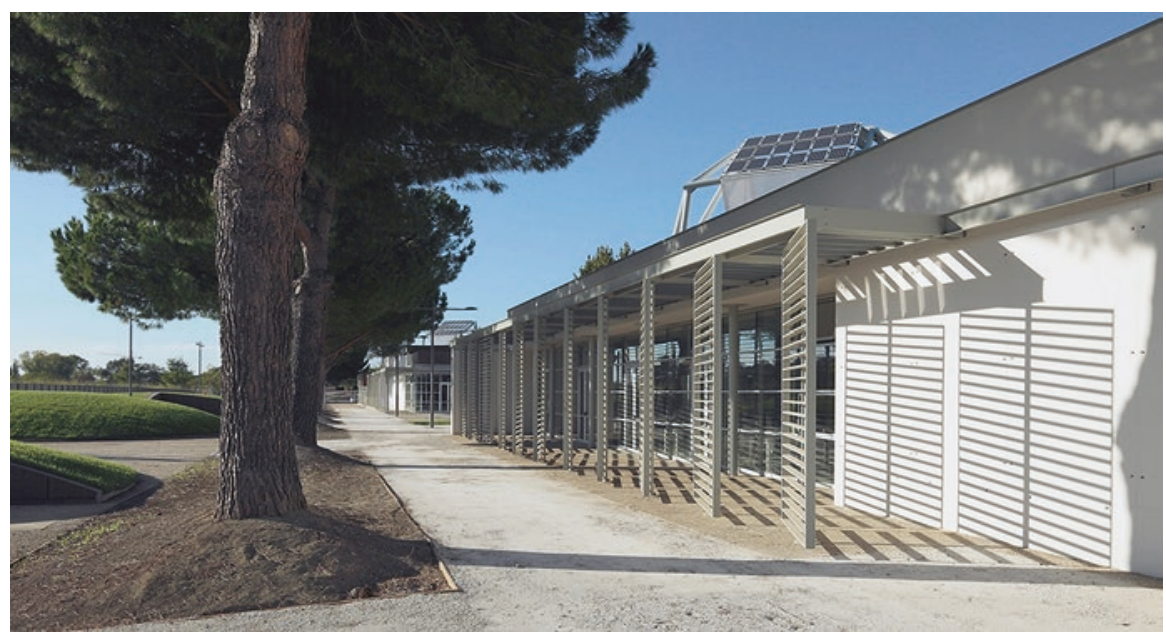

Fig. 12.6 Elsa Morante Cultural Center, Laurentino 38, Rome Capital. Photo by facetoface, Cupelloni's archive

control through advanced façade elements and simple earthworks. The analysis of solar radiation leads to the design of the horizontal, fixed brise-soleils (Cupelloni, 2011) (Fig. 12.6).

The sunscreens, thanks to the various angles, protect the glazed facades exposed to east/south/west from summer insolation, while allowing that daylight comes in during winter. The top skylights perform the same function. In addition, mobile vertical sun shades shield the glazed facades exposed to south/west, protecting the indoor spaces also against introspection from the outdoor (Panzini, 2009; cited in Cupelloni, 2011).

The limitation of heat lost is carried out by mounds on the north side and by walls realized with brick blocks made of mixtures of natural clay and wood flour, free from chemical additives. Panels with mineralized fir wood fibre, bounded with Portland concrete, have been used for the thermal and acoustic insulation of all concrete structures. The solution solves the thermal bridge between wall and ceiling, thanks to the double cast of concrete walls.

Interior and exterior concrete walls are painted with photocatalytic paint, based on TX Active with titanium dioxide, antismog, antibacterial and self-cleaning. Primary aluminium alloy profiles with thermal cut, with politermide and low-E insulating glasses, are used for the glazed facades. Active systems encompass advanced conditioning mechanical plants, made of machinery that uses HFC gas; low-energy and long-life lighting, exceeding the regulations for RAEE collection, recycling and disposal. Mechanical plants include a conditioning plant with recycling for the theatre; radiant panels associated with cooling plants with fan coils for the open space. Four PV plants are realized: three on huge "technological trees" for $10.26 \mathrm{kWp}$ and an energetic production of $13,500 \mathrm{kWh} / \mathrm{yr}$., in addition to the PV on the top of the theatre for $7.84 \mathrm{kWp}$, and a production of $11,500 \mathrm{kWh} / \mathrm{yr}$. The total 
production of the complex is $25,000 \mathrm{kWh} / \mathrm{yr}$., satisfying $20 \%$ of the needs, with a reduction of $\mathrm{CO} 2$ emissions equal to about 16,000 kg/yr. Finally, aiming at maximum draining surface and low maintenance costs, outdoor pavements and plant species have been selected with particular attention. Trees and grass lawns are watered through the rainwater collection system, harvesting a total of 250,000 litres (Cupelloni, 2011).

\subsection{Discussion}

\subsubsection{Similarities and Specificities}

In short, as proof of the consistency of the criteria and of environmental technological design tools, the cases described, despite the total diversity of place and programme, present strong similarities.

In addition to the evidence of linear development, fragmentation of elements, the seriality of parts, the alternation between full and empty, the continuity between external and internal, it is the methodological process and the innovative value that assimilate the three interventions.

The first case pursues the objective of preserving an asset of so-called "industrial archaeology", subject to monumental constraint, and at the same time applies technological innovation in terms of environmental sustainability, "by brilliantly solving the question of the client and above all by indicating, with tangible evidence of the realization, possible paths from the methodological and operational point of view for similar operations in which the contemporary, through technologies and compliant figures, can dialogue with history without inhibitions" (Associazione Nazionale Centri Storico-Artistici ANCSA, 2009).

The second tends to rediscover the memory of the place by proposing advanced formal and technological solutions, to respond functionally to new urban and social needs.

The third translates an unnecessary if not harmful expanse of asphalt, motivated only by the abstraction of urban standards, into an integrated system of valuable services, public greenery and relationship spaces, proposing a mode of redevelopment - for "densification" of services - certainly generalizable as an urban strategy based on the quality of an architecture that wants to affirm the strategic value of sustainable construction.

\subsection{Conclusions}

The description of the design experiments, lived through the always complex story of construction, highlights the plurality, the differences of a case study not at all homogeneous that does not allow generalizations and much less coded behaviours. 
The recovery of an industrial artefact, the reorganization of a historic road infrastructure, the regeneration of a peripheral area, in all cases, the intervention on the existing urban and architectural heritage is not a noble cause but an obligatory choice, subject to social degradation and urban inefficiency.

In the face of this problematic area, the issue of retraining goes far beyond its theoretical or technical definition, if we refer to the complex, difficult reality of our heritage in an active and not only defensive way. Beyond the schools of thought and the methods experienced in the cases carried out, the question can be defined - in a nutshell - as a "project measure", understood as a possible transformation.

The theme of "measure" therefore involves the question of the "relationship" with the good and its context, with the program and resources, with the chances and constraints. Mostly it is a relationship that does not follow a general rule and sometimes not even a canonical methodology. Too many variables within an infinite case study, complicated by specific intrinsic and boundary conditions, to establish a mode of relationship and therefore of intervention in advance. On the contrary, the only valid theory still seems to be that of the "case by case", understood as a subjective interpretation based on solid historical and analytical foundations.

"Case by case", of course, does not mean the agency or validity of any solution. Although both the prohibition - stated, originally, from Gustavo Giovannoni - to intervene in historical cities with contemporary architecture, and the radical doctrines of the so-called clean slate aimed at material and technological contrast and in any case detachment from historical matter, we must consider that the very notion of architectural or cultural good is not entirely shared. Some see it as a finished result, others as a work of pride, as a dynamic process.

In general - precisely from the experiences described - we can certainly decline at the theoretical level a conception of the project as today's stratification on the historical substrate, based on the reading and therefore on the readability of the history of the human presence and its signs on the territory, the city and its various components (Cupelloni, 2017).

The project can - and must - induce a real transformation action - understood systematically as "transformatio" - until the profound change of architectural and spatial characteristics, including the new terms - sometimes also the result of ancient lessons - of environmental, social and therefore economic sustainability, thought as a "temporary" moment of a historical cycle, flexible and open to constant modification.

\section{References}

Andreucci, M. B. (2015). Ritrovare la strada. / Via delle Sette Chiese. Roma Architettura del Paesaggio, 31, 62-63.

Associazione Nazionale Centri Storico-Artistici ANCSA. (2009). Premio Gubbio 2009. 42-43.

Costa, A. (2011). Il non luogo diventa piazza. Paesaggio urbano, 2, 46-53.

Cupelloni, L. (2010). Interpretation of historic sites. Beyond Standard Solutions. Detail, 1, 10. 
Cupelloni, L. (2011). Industrial archaeology and suburbs: Two cases of technological and environmental design. TECHNE, 2(2), 106-117. http://www.sitda.net/downloads/image/TECHNE/ Techne\%2002_PROGETTAZIONE\%20TECNOLOGICA.pdf. Accessed 25 July 2020

Cupelloni, L. (2014). Intervene on the ancient world. Lectures, theories and cases. LAF Landscape Architecture Frontiers, 12(6), 36-54.

Cupelloni, L. (2017). Ri-qualificare il Moderno. Materiali, temi e modi. In Materiali del Moderno. Campo, temi e modi del progetto di riqualificazione (pp. 25-61). Rome: Gangemi Editore.

Kaltenback, F. (2009). Città dell'altra economia all'ex Mattatoio. http://www.detail.de/artikel_ cupelloni-sanierung-schlachthof-rom_24791_It.htm Accessed 25 July 2020.

Nicolini, R. (2008). La città dell'Altra Economia. L'Architetto Italiano, 24, 8-11.

Panzini, F. (2009). Il Centro culturale "piazza Elsa Morante" al Laurentino 38. https://paesaggiocritico.wordpress.com/2010/10/04/il-centro-culturale- "piazza-elsa-morante" -al-laurentino-38xii-municipio/ Accessed 3 April 2020.

Randaccio, L. (2009). Struttura antisismica in acciaio prefabbricato. Imprese edili, 4, 22-26.

Toffolon, M. (2008). The alternative economy town in Rome. Glass in Its Style, 2, 4-11.

Open Access This chapter is licensed under the terms of the Creative Commons Attribution 4.0 International License (http://creativecommons.org/licenses/by/4.0/), which permits use, sharing, adaptation, distribution and reproduction in any medium or format, as long as you give appropriate credit to the original author(s) and the source, provide a link to the Creative Commons license and indicate if changes were made.

The images or other third party material in this chapter are included in the chapter's Creative Commons license, unless indicated otherwise in a credit line to the material. If material is not included in the chapter's Creative Commons license and your intended use is not permitted by statutory regulation or exceeds the permitted use, you will need to obtain permission directly from the copyright holder. 